\title{
Jesus, Nauk Maria de o governo local na fronteira Oeste: a rivalidade entre Cuiabá e Vila Bela no século XVIII
}

Denise A. Soares de Moura*

Dourados: Ed. Universidade Federal da Grande Dourados (UFGD), 2011. 197p.

A pesquisa sobre o governo local das câmaras tem longa tradição na historiografia portuguesa, mas apenas no século XXI tornou-se objeto de interesse da historiografia brasileira. Nos anos 1940 Edmundo Zenha escreveu uma obra específica sobre o município e o poder municipal no Brasil colônia. Mas foi um historiador anglo-saxão, John Russell-Wood, que na década de 1970 realizou densa pesquisa sobre a câmara de Vila Rica.

Em 2001, em um contexto de forte mudança de rumo teórico-metodológico da historiografia no Brasil (Fragoso, 2001; Sousa, 2003; Comissoli, 2006; Souza, 2007; Borrego, 2010; Monteiro, 2010), Maria Fernanda Bicalho publicou um texto repleto de sugestões de pesquisa sobre o governo das câmaras (Cunha; Fonseca, 2005; Zenha, 1948; Russell-Wood, 1977; Bicalho, 2001) que estimulou uma série de outras pesquisas.

Uma delas é o livro O governo local na fronteira Oeste, originalmente tese de Doutorado defendida na Universidade Federal Fluminense (UFF) em 2006, com o título Na trama dos conflitos: a administração na fronteira Oeste da América portuguesa (1719-1778). A autora, Nauk Maria de Jesus, é professora na Universidade Federal da Grande Dourados (UFGD) e especialista na História do Mato Grosso. Recentemente publicou também o Dicionário de História de Mato Grosso, com verbetes referentes ao período colonial.

O livro é uma versão resumida da volumosa tese e está formado por três capítulos distribuídos ao longo de 197 páginas que tratam de questões econômicas, políticas e administrativas das duas principais vilas situadas na fronteira oeste do Brasil: Vila Real do Cuiabá (fundada em 1727) e Vila Bela da Santíssima Trindade (de 1752).

\footnotetext{
* Universidade Estadual Paulista "Júlio de Mesquita Filho" (Unesp), Campus Franca. dmsoa1@yahoo. com.br
} 
Uma questão central da obra é a da disputa ocorrida essas duas câmaras, a partir de 1752, por privilégios e posições de precedência, algo que garantia status na estrutura administrativa e o acesso a melhores receitas orçamentárias. A criação da capitania de Mato Grosso, em 1748, é o pano de fundo dessa rivalidade.

O primeiro capítulo do livro disseca a estrutura humana e funcional das duas câmaras, identificando seu corpo de funcionários e fornecendo dados que permitem até mesmo medir a diferença com instituições camarárias de outras regiões.

Chamo atenção, por exemplo, para a constatação da autora de que existiu juiz de fora na Câmara de Vila Bela na época de sua fundação, o que significou a eliminação temporária da figura do juiz ordinário. Pesquisadores sobre o governo local das câmaras compreendem o quanto esse dado é importante por evidenciar as diferenciações regionais do poder do Império na América. Em São Paulo, por exemplo, há notícia de instalação de juiz de fora apenas em 1803.

Ou seja, nas regiões de fronteira com o Império hispânico, onde havia um ambiente bastante favorável para relações de interesses entre diferentes grupos étnico e sociais, a Coroa portuguesa pode ter tido maior zelo em manter a justiça nas mãos de funcionários régios, ao invés dos eleitos localmente, como acontecia com os juízes ordinários.

Como mostra a autora, em Vila Real ou em Vila Bela, assim como aconteceu em Vila Rica, não houve a formação de um corpo de funcionários oriundos e aparentados nas elites dos primeiros conquistadores. No caso das duas câmaras do Mato Grosso, esses funcionários foram comerciantes, também proprietários de terras e engenhos e criadores de gado, mas sem o verniz das linhagens. Alguns foram oficiais de ofício, sapateiros por exemplo, que com as oportunidades próprias de toda área fronteiriça e de ocupação tardia, ascenderam socialmente por serviços prestados à Coroa ou pela labuta cotidiana de mercador.

O capítulo 2 aborda o período de regência da câmara de Vila Real do Cuiabá e sua atuação. O Oeste do território do Brasil pertencia à capitania de São Paulo, e seu governador, Rodrigo César de Menezes, associado com a ordem municipal, trabalhou para a efetiva incorporação da região ao Império português. Essa iniciativa conjunta deu origem, em 1748, às capitanias de Goiás e Mato Grosso.

Nesse processo de reordenamento administrativo da região houve uma série de conflitos com a população indígena local, especialmente os Paiaguás, 
envolvidos em negócios de contrabando, extravios do ouro e comércio de mão de obra cativa indígena. Essas lutas contra o gentio, que na realidade significavam também o combate das próprias pretensões castelhanas na zona fronteiriça, marcaram a identidade de vassalos da câmara de Vila Real. Ao arriscar suas vidas nos confrontos com Paiaguás e espanhóis, esses vassalos se viam como executores de determinados serviços e, portanto, dotados de certos direitos.

O capítulo 3 focaliza a rivalidade que existiu entre as duas câmaras no processo de implantação da ordem administrativa na fronteira Oeste. Quando de sua fundação, Vila Bela alcançou uma série de honras e privilégios que na realidade Vila Real considerava como seus de direito, tendo em vista os vários serviços que havia prestado ao rei na ocasião do estabelecimento dos primeiros povoamentos, como o combate aos índios e aos espanhóis. Vila Bela foi agraciada com benefícios e isenções, status de "vila-capital", tornando-se sede do aparato administrativo e fiscal da capitania e recebendo em seu território instituições como a Ouvidoria, a Intendência do ouro e a Provedoria da Real Fazenda.

Embora a historiografia sobre a ordem municipal viva atualmente um início de renovação, com o surgimento dos primeiros trabalhos que concentram suas investigações sobre um funcionário específico (Schmachtenberg, 2012), O governo local na fronteira Oeste, diferindo da tradição monográfica portuguesa e mesmo dos primeiros trabalhos concluídos no Brasil, focalizou relações intercamarárias, o que é um ponto de originalidade da obra.

Essas rivalidades entre câmaras não foram específicas do Mato Grosso. Uma série de outras do mesmo gênero aconteceram e podem ter sido um dos últimos esforços de reordenamento administrativo do Império português em seu período tardio (1790-1820). Desde 1768 a vila de Santos disputou precedência com a de São Paulo. O ilustrado Marcelino Pereira Cleto chegou a defender a ideia de que a vila de Santos fosse alçada à condição de sede administrativa da capitania.

Mesmo em 1812 a transferência da sede da comarca da vila de Paranaguá para a de Curitiba foi motivo de bastante mal-estar entre essas duas câmaras (Severino, 2009). Houve, portanto, um contexto de transferência de poderes municipais no período colonial tardio que ainda não foi suficientemente pesquisado.

O que faltou no livro, embora apareça na tese, foi a melhor explicitação da terminologia administrativa do período. Alguns pesquisadores vêm se dedicando a esse aspecto bastante revelador da lógica hierárquica do antigo 
regime (Damasceno, 2003), o que contribui para um maior rigor nas conclusões sobre a história administrativa da época moderna.

A expressão "vila-capital", ao se referir à câmara principal ou à condição administrativa disputada por ambas as câmaras, poderia ter sido mais problematizada. Essa expressão parece não ter feito parte da terminologia administrativa oficial da época. Os dicionaristas Raphael Bluteau (1728) e Antonio de Morais Silva (1798) definem como unidades administrativas os julgados, vilas, cidades, comarcas e paróquias. Capital não é definida como unidade regional -administrativa. Neste caso, a expressão "capital” que aparece nas representações, ofícios e petições analisados pela autora não teria sido, talvez, uma invenção dos próprios habitantes das vilas em disputa? Ou seja: em que medida a escrita pública local não foi responsável por reelaborar a terminologia administrativa da época, criando novas expressões que atribuíam status a uma localidade?

Assim, do mesmo modo como os habitantes da colônia foram responsáveis por criar outras designações sociais, esse mesmo processo pode ter ocorrido nas designações urbano-administrativas, como o O governo local na fronteira Oeste sugere ao leitor, deixando ainda ao pesquisador em História administrativa uma questão nova para ser problematizada por meio dos escritos municipais.

\section{REFERÊNCIAS}

BICALHO, Maria Fernanda Baptista. História do Brasil. História Moderna, História do Poder e das ideias políticas. In: ARRUDA, J. J.; Fonseca, L. A. (Org.) Brasil-Portugal. História: Agenda para o milênio. Bauru, SP: Edusc; São Paulo: Fapesp; Portugal: ICCTI, 2001. p.143-166.

BORREGO, Maria Aparecida de Menezes. A teia mercantil: negócios e poderes em São Paulo (1711-1765). São Paulo: Alameda, 2010.

COMISSOLI, Adriano. Os "homens bons" e a câmara de Porto Alegre (1767-1808). Dissertação (Mestrado em História) - Departamento de História, Universidade Federal Fluminense. Niterói, 2006.

CUNHA, Mafalda Soares; FONSECA, Teresa (Org.) Os municípios no Portugal Moderno: dos forais manuelinos às reformas liberais. Évora: Colibri; Cidehus/EU, 2005.

DAMASCENO, Claudia. Funções, hierarquias e privilégios urbanos: as concessões dos títulos de vilas e cidades na capitania de Minas Gerais. Varia História, Belo Horizonte: UFMG, v.29, p.39-51, jan. 2003. 
FRAGOSO, João et al. O antigo regime nos trópicos: a dinâmica imperial portuguesa. Rio de Janeiro, Civilização Brasileira, 2001.

MONTEIRO, Livia Nascimento. Administrando o bem comum: os "Homens bons" e a câmara de São João del Rey, 1730-1760. Dissertação (Mestrado em História Social) - Departamento de História, Universidade Federal do Rio de Janeiro. Rio de Janeiro, 2010.

RUSSELL-WOOD, A. J. R. O governo local na América Portuguesa: um estudo de divergência cultural. Revista de História, São Paulo: Universidade de São Paulo, n.9, p.25-79, jan.-mar. 1977.

SCHMACHTENBERG, Ricardo. “A arte de governar”: redes de poder e relações familiares entre os juízes almotacés na câmara municipal de Rio Pardo/RS, 1811-c.1830. Tese (Doutorado em História) - Departamento de História, Universidade do Vale do Rio dos Sinos. Porto Alegre, 2012.

SEVERINO, Caroline Silva. A dinâmica do poder e da autoridade na comarca de Paranaguá e Curitiba, 1765-1822. Dissertação (Mestrado em História) - Unesp. Franca, 2009.

SOUSA, Avanete Pereira. Poder local, cidade e atividades econômicas (Bahia, século XVIII). Tese (Doutorado em História) - Departamento de História, FFLCH, Universidade de São Paulo. São Paulo, 2003.

SOUZA, George Félix Cabral de. Elite y ejercicio del poder en el Brasil colonial: la Cámara municipal de Recife (1710-1822). Tesis (Doctorado en História) - Departamento de História, Universidad de Salamanca, 2007.

ZENHA, Edmundo. O município no Brasil, 1532-1700. São Paulo: Instituto Progresso Editorial, 1948.

Resenha recebida em 7 de maio de 2013. Aprovada em 22 de outubro de 2014. 